\title{
TECNOLOGIAS DA INFORMAÇÃO E COMUNICAÇÃO A SERVIÇO DO TRABALHO COLABORATIVO, INOVAÇÕES SOCIOEDUCACIONAIS E DESENVOLVIMENTO LOCAL
}

\author{
SILVA, Luciene Aparecida da \\ Mestranda em Gestão Social, Educação e Desenvolvimento Local pelo Centro \\ Universitário UNA, Analista Educacional da Superintendência Regional de Ensino - \\ Metropolitana C, lucie@uai.com.br \\ MACHADO, Lucília Regina de Souza \\ Coordenadora do Curso de Mestrado em Gestão Social, Educação e Desenvolvimento \\ Local do Centro Universitário UNA, 1smachado@uai.com.br
}

RESUMO: Este ensaio compreende a discussão dos conceitos tecnologias da informação e comunicação (TICs), trabalho colaborativo, inovações socioeducacionais e desenvolvimento local à luz da problematização teórica dos pontos de convergência e divergência entre o paradigma educacional emergente e a dicotomia global/local. Por meio desta interlocução são discutidos as potencialidades e os desafios decorrentes da incorporação das TICs pelo mundo do trabalho e pelo campo educacional tomando-se como referência premissas sobre seu papel na indução do trabalho colaborativo, de inovações socioeducacionais e do desenvolvimento local.

Palavras-chave: tecnologias da informação e comunicação; trabalho colaborativo; educação; desenvolvimento local.

\section{INFORMATION TECHNOLOGY AND COMMUNICATION IN THE SERVICE OF WORKING TOGETHER, SOCIAL AND EDUCATIONAL INNOVATION AND LOCAL DEVELOPMENT}

\begin{abstract}
This test includes the conceptual analysis of key expressions: information and communication technologies (ITCs), collaborative work, social, educational innovation and local development. The analysis is the unifying theoretical questioning of the points of convergence and divergence between the educational paradigm emerging dichotomy and global / local. The dialogue initiated discusses the main components of the multidimensional potential and challenges posed as a tonic and an attribute of incorporation of ITCs into the workplace and the educational field in the garb of inducing agent of the collaborative work, the wealth of innovative social, educational and local development.
\end{abstract}

Key - words: information technology and communication in - collaborative work education - local development. 


\section{Apresentação}

Os fenômenos do livre comércio e da livre movimentação do capital financeiro, mais conhecidos como globalização da economia, levaram não apenas à dissolução das fronteiras nacionais, mas a inúmeras outras transformações, que vêm sendo experimentadas pela humanidade em todos os campos da vida social.

As tecnologias de informação e comunicação (TICs) vêm servindo de suporte e motor destas transformações, estando na origem do advento da chamada economia baseada no conhecimento, que tem forçado a obsolescência da capacidade humana de produzir e exigido maior capacidade de aprendizado permanente e ao longo da vida. Este tem se revelado como um dos maiores desafios a ser enfrentados pelas sociedades globais neste século XXI.

Quanto aos profissionais da educação, tal demanda reveste-se de um caráter ainda mais premente, por ser o conhecimento, com todas as suas dimensões, uma das matériasprimas fundamentais ao trabalho pedagógico e um dos principais elementos de constituição da força de trabalho docente.

O conhecimento, hoje, mutável e abundante, não mais comporta a disciplinaridade estanque e o enrijecimento ou padronização dos usos dos tempos e espaços de aprendizagens.

Portanto, outro perfil profissional torna-se necessário, sobretudo, no cenário educacional: um profissional predisposto a aprender sempre e apto a atuar colaborativamente nos processos educacionais intra e extra-escolares, assumindo o papel de agente promotor e disseminador das inovações socioeducacionais e do desenvolvimento local, enfrentando e transpondo o desafio de educar na e para a congruência dos três tempos, com e para o uso social dos meios tecnológicos.

Em face deste contexto, pautando-se na análise conceitual e na problematização teórica dos pontos de convergência e divergência entre o paradigma educacional emergente e a dicotomia global/local, este ensaio apresenta uma discussão sobre as potencialidades e desafios postos pela incorporação das TICs ao mundo do trabalho e ao campo educacional considerando-se a expectativa de que estas sejam agentes indutores do trabalho colaborativo, de inovações socioeducacionais e do desenvolvimento local.

\section{Aprendizagem ao longo da vida e conceitos subjacentes}

O Relatório da Comissão Internacional sobre Educação para o Século XXI da UNESCO, organizado por Jacques Delors em 1993 e intitulado Educação - um tesouro a descobrir - constitui-se no principal referencial dos debates, que se intensificam em torno da educação a partir dos anos 1990. Este documento discute os conceitos de educação ao longo da vida e os denominados quatro pilares da educação para o século XXI: aprender a conhecer, aprender a fazer, aprender a viver juntos e aprender a ser (Delors, 2001). 
Belloni (2001a, p. 5) citando (Carmo, 1997 et al.) esclarece que o conceito de educação ao longo da vida "[...] refere-se a uma educação mais integrada aos locais de trabalho e às expectativas e necessidades dos indivíduos".

Silva (2008, p. 369) afirma que:

A Educação ao longo de toda a vida se refere à mudança da noção de qualificação, pautada em uma formação única, para a noção de competência, que se relaciona a uma formação dinâmica, flexível, condizente com a ênfase atual no trabalho em equipe, na capacidade de iniciativa, na valorização de talentos e aptidões (grifos da autora). [...]

Face às demandas das chamadas sociedades globais da informação, que se supõem sejam centradas numa economia baseada no conhecimento, a educação passou a ser concebida como instrumento de mobilidade ascendente de indivíduos e nações e de democratização de oportunidades, colocando em cheque a suficiência da formação inicial dos indivíduos. Este seria, então, o principal fator impulsionador das crescentes demandas por formação ao longo da vida, conceito que segundo (Belloni, 2001a, p. 6) veio abrir a educação à "contribuição de todos os atores sociais", exigindo "uma forte sinergia entre o campo educacional e o campo econômico no sentido de promover a criação de estruturas de formação continuada mais ligadas aos ambientes de trabalho."

Neste contexto, segundo Machado (1994, p. 183), a informação passa a ser vista como força motriz da produção humana "[...] e ganha mais em qualificação quem estiver mais próximo e souber dominar o circuito completo de seu processamento", exercitando a capacidade profissional de transposição do aprender a fazer para o aprender a aprender. Isto implica, segundo esta autora, a necessidade de "[...] desenvolver a capacidade de inovar, de produzir novos conhecimentos e soluções tecnológicas adequadas às necessidades sociais" a partir do uso criativo das informações.

Tal demanda social passa a compor uma série de novas exigências aos sistemas educacionais, dentre as quais se destaca a incorporação das TICs aos processos pedagógicos escolares.

Assiste-se, desde então, a uma mobilização de organismos internacionais e nacionais em torno do debate, elaboração, implementação e apoio às políticas de fomento à inclusão sociodigital, dirigida especialmente às instituições educacionais.

Entretanto, tal iniciativa apresenta-se tão promissora quanto desafiadora para a gestão e a governança educacional, sobretudo, pelo fato de requerer quebra de paradigmas, mudança de postura e intenso envolvimento e participação de todos os atores envolvidos nos processos educativos intra e extra-escolares. $\mathrm{O}$ que noutros termos equivale à exigência de um perfil profissional docente que corrobore e seja congruente com a capacidade de aprender a aprender continuamente. 


\section{TICs, perfil profissional docente e novas educações}

Perrenoud (2000) aponta a capacidade de utilizar as TICs na escola como uma das dez novas competências para ensinar inerentes à profissionalização do professor no século XXI.

Entretanto, o autor esclarece que não se trata de colocá-las no centro da evolução do ofício da docência. O que concerne ao professor é saber fazer uso de editores de textos, explorar as potencialidades didáticas dos programas em relação aos objetivos do ensino, aprimorar sua capacidade de comunicar-se a distância por meio da telemática e utilizar as ferramentas multimídia no ensino.

Nesta direção, a formação docente assumiria uma nova configuração, ressignificando-se teórica e praticamente. Este processo de remodelagem profissional abarcaria diversas dimensões: o ato de se formar, a maneira ou a forma como isto ocorre, o conjunto dos conteúdos implicados e o efeito deste processo que se estende num contínuo, ao longo de toda a vida do profissional docente.

Transversais às atuais transformações societárias, as TICs não são, de forma alguma, componentes neutros. Ao contrário, são produzidas e são, concomitantemente, produtoras de mudanças sociais cada vez mais profundas no contexto das sociedades contemporâneas. Portanto, constituem-se, também, como componentes transversais à formação e atuação profissional docente, evocando, conforme anunciam Pretto e Pinto (2006), "novas educações".

Para Belloni (2001a, p. 65):

[...] as TICs são fundamentalmente aquelas (tecnologias) - recheadas de informática - que permitem a estocagem e a transmissão de informações em quantidade, qualidade e velocidade inéditas na história da humanidade e que têm como característica essencial a imaterialidade de sua matéria-prima, a informação (grifo e negrito da autora).

Noutras palavras, Belloni (2001b, p. 21) afirma que “[...] as TICs são resultado da fusão de três grandes vertentes técnicas: a informática, as telecomunicações e as mídias eletrônicas".

A autora (2001a, p. 58), ao descrever os atributos centrais das TICs, salienta que estes demandam sobremaneira o "saber como usá-las".

O primeiro diz respeito à interatividade, “[...] característica técnica que significa a possibilidade de o usuário interagir com uma máquina"; ele pode executar um comando e obter respostas do programa utilizado; pode controlar as ações e a forma como este programa funciona.

O segundo se refere ao ineditismo das possibilidades de comunicação proporcionadas por estas tecnologias mediante as formas de interação, levando à "[...] ação recíproca entre dois ou mais atores onde ocorre intersubjetividade". Isto pode se dar de forma direta ou mediatizada, diferida ou simultânea. 
Evans e Nation (1993, p. 199) conceituam tecnologia como "[...] uma forma de conhecimento" e salientam que os artefatos tecnológicos sem o "saber como" usá-los, consertá-los ou fazê-los, revestem-se de inutilidade.

Linard (1996, p. 191) define tecnologia como "[...] um conjunto de discursos, práticas, valores e efeitos sociais ligados a uma técnica particular num campo particular”.

Nota-se aí uma aproximação entre a definição que Linard aplica ao conceito de tecnologia e a conceituação que o filósofo e sociólogo francês Pierre Lévy atribui às denominadas tecnologias da inteligência, conforme define $\operatorname{Moura}^{1}$ (2001, p. 3), parafraseando Lévy:

Uma tecnologia da inteligência é tudo aquilo de que lançamos mão (consciente ou inconscientemente) na nossa comunicação, na elaboração do nosso pensamento, na criação de nossos conhecimentos e que, além de nossos sentimentos e afetos, suportam a nossa inteligência: são as linguagens, os sistemas de signos, os recursos lógicos, os instrumentos dos quais nos servimos.

Lévy (1994) esclarece que com a aceleração da produção dos conhecimentos científicos e técnicos a partir do fim do século XVIII e uma consequente profusão das tecnologias digitais, houve, a partir do século XX, a expansão da mundialidade, marcada por uma progressiva descoberta de sua diversidade e complexidade.

Segundo o autor, este movimento fez emergir o ciberespaço, constituído pela interconexão em tempo real de todos os computadores do planeta. Deste provém, então, a inteligência coletiva, que por sua vez representa a "[...] condição de possibilidade das soluções práticas para os problemas de orientação e aprendizado no universo do saber em fluxo" e se constitui no principal elemento de fomento à cibercultura (Lévy, 1994, p. 7).

Para Moura (2001, p. 6), o reconhecimento e enriquecimento mútuos das pessoas, constituem a base fundamental da inteligência coletiva, criando "a perspectiva de um laço social construtivo e cooperativo, onde cada um, embora não saiba tudo, pode colaborar com aquilo que sabe."

A incorporação desta nova conceituação à educação significa, conforme Lévy (1994), que "toda e qualquer política de educação deverá levar em consideração" os aspectos inerentes à cibercultura latente do ciberespaço como canal propagador da inteligência coletiva.

Isto significa que os modelos educacionais em vigência não têm dado conta de suprir as demandas sociais, que se intensificaram e se aprofundaram a partir das três décadas finais do século passado, denominadas por Hobsbawm (1995) de Décadas de Crise ou do Desmoronamento Final.

Portanto, a educação e os demais processos sociais encontram-se diante de grandes desafios. Um dos quais compreende a transposição do ser individual enrijecido para o ser coletivo em face de um contexto social que urge pelo novo e que, rapidamente,

${ }^{1}$ Disponível em http:// www.ddic.com.br. Acesso em: 25/05/2009.

V. $7 \mathrm{~N}^{\circ}$ 3, dezembro, 2009 
torna-se obsoleto. Outro, decorrente do primeiro, refere-se ao próprio uso e incorporação das TICs aos processos educacionais escolares como componentes de fomento à cultura do trabalho colaborativo potencializador da formação docente continuada e comprometida com a dinâmica do desenvolvimento local.

Neste cenário social, povoado de permanentes e aceleradas mutações tecnológicas, organizacionais e das relações mercadológicas, "[...] a capacidade de gerar e absorver inovações vem sendo considerada, mais do que nunca, crucial para que um agente econômico se torne competitivo" (Lemos, 1999, p. 122).

Para Machado (1994, p. 186), "a capacidade de inovar sintetiza competências adquiridas pelo domínio de conhecimentos e habilidades científico-técnicas, sociais e metodológicas, dentro de um sistema de relações sociais e técnicas" favorecendo "o despertar da consciência e dos valores emancipadores do ser humano, tais como autonomia e liberdade".

De Masi (2005, p. 26) afirma que num processo criativo "[...] o verdadeiro sujeito histórico da criação não é o homem, mas a sociedade: a sociedade criativa" (grifo e negrito do autor) e que a maior parte das produções ou invenções humanas é obra de grupos e de coletividades e não de gênios individuais.

Esta proposição permite afirmar que “[...] a inovação é o substrato dos transbordamentos de conhecimentos" e que sempre esteve presente ao longo da trajetória humana sobre a Terra (Farfus e Rocha, 2007, p. 17). As autoras (2007, p. 18), citando Elias (1994, p. 19), afirmam que: [...] "Não há dúvida de que cada ser humano é criado por outros que existiam antes dele. Ele cresce e vive como parte de uma associação de pessoas, de um todo social - seja este qual for [...], e onde se localize passado, presente ou futuro." E concluem seu pensamento argumentando que "[...] a articulação dos indivíduos em rede, trabalhando de forma sintonizada e harmônica" constitui, de fato, o mecanismo potencializador da definição enunciada por Elias.

\section{Trabalho colaborativo e desenvolvimento local - potencialidades e desafios}

Embora a expressão trabalho colaborativo tenha sido qualificada como um conceito em construção e relativamente novo, haja vista a restrita produção científica disponível, os debates e estudos sobre ele têm se beneficiado ou se intensificado pelas discussões sobre o conceito de redes e suas relações intrínsecas.

Sobral (2005, p. 5) afirma que:

O tema conhecimento e redes se destaca, pois a própria sociedade hoje é pensada por meio das redes. Castells ${ }^{2}$, no seu livro $A$ sociedade em rede, considera que a partir da década de 1970 nossas sociedades ingressaram em um novo contexto histórico nomeado por ele de "era da informação", pois as tecnologias da informação vêm revolucionar o modo de produção e de vida das sociedades.

\footnotetext{
${ }^{2}$ CASTELLS, M. A Sociedade em rede. Volume I, São Paulo: Paz e Terra, 1999.
}

V. $7 \mathrm{~N}^{\circ}$ 3, dezembro, 2009 
[...] Latour afirma que a tecnociência tem características de redes, com laçadas e nós, fios e malhas, significando que as redes não só envolvem aqueles que estão inseridos nelas, mas também as milhares de pessoas que não fazem a ciência, mas que dela dependem, no seu dia a dia, ou nela depositam seus créditos, ou ainda têm ela como ponto de referência para o julgamento dos seus pensamentos, atos e crenças, ou mesmo desenvolvam uma cadeia de associações para contrapor-se a ela ou criar outras formas de conhecimento. ${ }^{3}$

Segundo Martinho (2003), o conceito de rede define uma forma de organização coordenada e colaborativa entre elementos distintos que se serve da articulação conjuntural e horizontal em prol do alcance dos objetivos compartilhados pela coletividade e totalidade dos elementos que a constitui. Trata-se de um fenômeno social cujos princípios organizativos pautam-se na autonomia, horizontalidade, cooperação, democracia e conectividade.

A integralização destes elementos pressupõe um movimento sinérgico, catalisador e, ao mesmo tempo, retroalimentador da mobilização social, participação, isonomia, confiança e cultura. Neste contexto, os artefatos tecnológicos são ferramentas que ocupam um importante lugar. No entanto, é preciso considerar que estes são apenas suporte material subordinado ao uso e às decisões humanas.

A capacidade de conectividade define as ligações ou linhas entre os pontos ou nós de uma rede, abarcando as propriedades de interatividade, expansão, multiplicação, multidimensionalidade, transitividade, reciprocidade nas relações estabelecidas, plasticidade e dinamicidade do movimento permanente que se traduzem na própria conectividade, conforme esclarece Martinho (2003, s/p.).

Para este autor, "fazer conexões é o mesmo que construir vias de comunicação", já que a circulação da informação constitui-se no fluido que mantém ou abastece a rede e é responsável pela organização das ações. Assim, o que se depreende dos argumentos deste autor é que não há ação colaborativa sem a troca recíproca de informações. Em decorrência, os denominados pontos hiperconetores revelam-se na mais poderosa propriedade da rede, sobretudo, no que se refere à mobilização social.

A organização estrutural da rede constitui-se, portanto, na sua característica mais importante, pois um conjunto de nós desconectados nada mais é que pontos dispersos no espaço. Por conseguinte, não é possível identificar o centro de uma rede. Isto seria antagônico ao princípio da horizontalidade e da autonomia. A palavra centro remete à idéia de controle unilateral e se opõe diretamente ao princípio da autonomia.

Neste sentido, o trabalho colaborativo tomado como atributo da formação de redes sociais e digitais, além de constituir-se numa promissora estratégia de formação continuada em serviço, assume o papel de agente promotor e disseminador das inovações socioeducacionais e do desenvolvimento local. Representa também condição imprescindível à ruptura com o modelo educacional verticalizado.

O termo desenvolvimento local é polissêmico e seu arcabouço conceitual encontra-se ainda em construção. A aproximação mais recorrente (Oliveira, 2001) diz respeito a um

${ }^{3}$ LATOUR, B. Ciência em ação. São Paulo: UNESP, 2000.

V. $7 \mathrm{~N}^{\mathrm{o}}$ 3, dezembro, 2009 
processo que guarda relações dialéticas com o processo de globalização, numa dupla relação de convergência e de diferenciação, apoiado no poder local de uma comunidade. Tem como força motriz a mobilização comunitária em todas as suas expressões (econômica, social, política, cultural) proveniente da interatividade e da participação cidadã. $\mathrm{O}$ lócus desta ação sinérgica se dá na comunidade local por meio de práticas gestionárias coletivas que visem o bem comum e a qualidade de vida.

O trabalho colaborativo compreende a prática de compartilhamento, de trocas e auxílios recíprocos e contínuos que se realizam, visando satisfazer às necessidades coletivas, conformando uma nova qualidade nos processos e relações sociais, operando mudanças no contexto sociocultural em que os cidadãos atuam. Pressupõe o desenvolvimento da capacidade de trabalhar em equipe, a solidariedade, a abertura às diversidades de pontos de vista, o intercâmbio e a interlocução permanentes. Portanto, a efetividade da incorporação deste conceito à educação, sobretudo, à escolar, demanda a reconfiguração conceitual e prática da cultura docente.

Segundo Pérez Gómez (2001), a cultura docente expressa um conjunto de valores, sentimentos, significados, práticas, rituais, crenças, modos, expectativas e concepções que circundam a vida individual e coletiva e são compartilhados socialmente pela comunidade docente.

A cultura do trabalho docente colaborativo mediado por TICs refere-se a um conjunto de padrões de comportamento, crenças, conhecimentos, costumes etc. que distinguem os indivíduos, profissionais e cidadãos que empregam estas tecnologias como mecanismo ou recurso de mediação nas trocas de experiências que realizam e no compartilhamento e construção de saberes que necessitam para seu exercício profissional e de cidadania.

Portanto, a cultura docente de trabalho colaborativo mediado pelas TICs é tomada como um aporte à prática docente reflexiva e colaborativa e demanda autonomia intelectual e aprendizagem compartilhada. Nasce e se desenvolve no âmbito de um processo sustentado pela reciprocidade, mutualidade, cooperação e colaboração via emprego das TICs, conformando uma inteligência docente coletiva contextualizada no ciberespaço, rompendo com a dicotomia global/local.

Nesta perspectiva, as práticas de fomento e disseminação das inovações socioeducacionais se distanciam do modelo difusionista de inovações e se aproximam do modelo de translação sistematizado por Latour (2000), cujos elementos estruturais incorporam a necessidade da ação coletiva fundamentada na lógica das redes.

O desenvolvimento local, ao se organizar e se auto-regular pela base da sociedade, indo além dos aspectos econômicos, implica em mudança de foco, por estar centrado nas pessoas e no seu ambiente. Põe à mostra a dimensão territorial dos processos econômicos, chamando a atenção para o espaço onde as pessoas vivem e podem participar diretamente e para o conhecimento que elas têm da sua realidade. Pressupõe participação comunitária, envolvimento direto dos cidadãos no enfrentamento das demandas emergentes e na gestão dos recursos localmente disponíveis.

Finalmente, cabe ressaltar que a lógica de trabalho colaborativo concebida como elemento indutor do desenvolvimento local sustentável não comporta a adoção do V. $7 \mathrm{~N}^{\circ}$ 3, dezembro, 2009 
modelo difusionista de inovações socioeducacionais. Este modelo se pauta na "difusão das inovações via repasses" e contrapõe-se à dinâmica de formação continuada em serviço referenciada na prática reflexiva, como componente básico da cultura do aprendizado coletivo e ao longo da vida.

\section{Considerações Finais}

A discussão conceitual acima realizada sugere a ressignificação pela escola e por toda a sociedade dos tempos e espaços de aprendizagem, a abolição da hierarquização dos saberes escolares e a flexibilização disciplinar dos currículos.

Fomentar a concretização de novas educações requer, sobretudo, uma urgente ruptura com o modelo verticalizado, racional-burocrático das instituições escolares e com a gestão e organização curricular amestradas, conforme anunciam Pretto e Pinto (2006). Requer, enfim, a superação do desafio de educar com e para o uso criativo dos meios tecnológicos, reivindicando a articulação e atuação dos órgãos técnico-pedagógicos escolares e extra-escolares com processos de inovação didáticos e educacionais que emergem a partir destas novas interações.

Tais inovações devem ser capazes de promover a transposição da dicotomia tempo espaço escolar e social, de forma tal que todos os espaços sociais, gradativamente, convertam-se em salas de aula, sem imposição de fronteiras espaço-temporais e limitação quantitativa e qualitativa das aprendizagens compartilhadas.

Por tais motivos, cabe salientar a importância do fomento ao trabalho colaborativo como agente indutor da formação docente continuada comprometida com a dinâmica de desenvolvimento local. Esta abriga a colaboração mediada pelo diálogo permanente em torno das questões peculiares à realidade de cada local, considerando os sujeitos e suas inquietações, expectativas, concepções, espaços, singularidades, identidades, saberes, bem como o modo de fazer e sentir das pessoas e das comunidades.

\section{Referências Bibliográficas}

BELlONI, Maria Luíza. Educação a Distância. Campinas, SP: Autores Associados, 2. ed., 2001a. (Coleção Educação Contemporânea). 126 p.

O Que é Mídia educação. Campinas, SP: Autores Associados, 1 ed., $2001 \mathrm{~b}$. (Coleção: Polêmicas do Nosso Tempo). 100 p.

DELORS, Jaques (Org.). Educação: um tesouro a descobrir. Relatório para a Unesco da Comissão Internacional sobre Educação para o Século XXI. Tradução José Carlos Eufrázio. São Paulo: Cortez; Brasília: MEC/ UNESCO, 5. ed. 2001. 288 p.

DE MASI, Domenico. Criatividade e Grupos Criativos. Descoberta e Invenção. Rio de Janeiro: Sextante, 2005. V. 1. 464 p. 
EVANS, Terry. e NATION, Daryl. Educational Technologies: Reforming Open and Distance Education", in Koogan/Page, 1993. 231 p. . Reforming Open and Distance Education. Londres:

FARFUS, Daniele (org.) e ROCHA, Maria Cristhina de Souza (org.). Inovações Sociais. Curitiba: SESI/SENAI/IEL/UNINDUS, 2007. (Coleção Inova; v. 2). 246 p.

HOBSBAWM, Eric. Era dos Extremos: O breve século XXI (1914 - 1991). São Paulo: Companhia das Letras, 1995. Tradução de Marcos Santarrita. 598 p.

LATOUR, Bruno. Ciência em ação: como seguir cientistas e engenheiros sociedade afora. São Paulo: Editora UNESP, 2000. 258 p.

LEMOS, Cristina. Inovação na Era do Conhecimento. In: LASTRES e ALBAGLI (orgs.). Informação e Globalização na Era do Conhecimento. Rio de Janeiro: Campus, 1999. p. $122-144$.

LÉVY, Pierre. Cybercultura. São Paulo: Editora 34, 1994. 260 p.

LINARD, Monique. Dês Machines et dês Hommes. Paris: L'Harmattan,1996. 288 p.

MACHADO, Lucília Regina de Souza. A Educação e os Desafios das Novas Tecnologias. In: FERRETTI, Celso João. ZIBAS, Dagmar M. L. MADEIRA, Felícia R. FRANCO, Maria Laura P. B. (Orgs.). Novas tecnologias, trabalho e educação: um debate multidisciplinar. Petrópolis, RJ: Vozes, 1994. p. 169 - 188.

MARTINHO, Cássio. Redes: uma introdução às dinâmicas da conectividade e da autoorganização. Brasília, WWF Brasil, 2003.

MOURA, Arthur Hyppólito de. A Inteligência Coletiva. Artigo originalmente publicado na revista Marketing Industrial, N ${ }^{\circ} 18$, Ano 7 - 2001. Disponível em: http:// www.ddic.com.br. Acesso em: 25/05/2009. p. 1 - 7.

PRETTO, Nelson de Luca e PINTO, Cláudio da Costa. Tecnologias e novas educações. Revista Brasileira de Educação. V. 11. N 31. jan./abr. 2006. p. 19 - 30.

OLIVEIRA, Francisco de. Aproximações ao enigma: o que quer dizer desenvolvimento local? São Paulo, Pólis; Programa Gestão Pública e Cidadania/EAESP/FGV, 2001. 40p.

PERRENOUD, Philippe. Dez novas competências para ensinar. Tradução: Patrícia Chittoni Ramos. Porto Alegre: Artes Médicas Sul, 2000. p. 162.

PÉREZ GÓMEZ, A. A cultura escolar na sociedade neoliberal. Tradução: Ernani Rosa Porto Alegre, Artmed, 2001.

SILVA. Lenildes Ribeiro. UNESCO: Os quatro pilares da "educação pós-moderna". Inter-Ação: Rev. Fac. Educ. UFG, 33 (2). p. 359-378, jul./dez. 2008.

SOBRAL. Fernanda A. da Fonseca. Prefácio. In: Baumgarten (org.). Conhecimentos e Redes: sociedade, política e inovação. Porto Alegre, Editora da UFRGS, 2005. p. 191.

V. $7 \mathrm{~N}^{\circ}$ 3, dezembro, 2009 